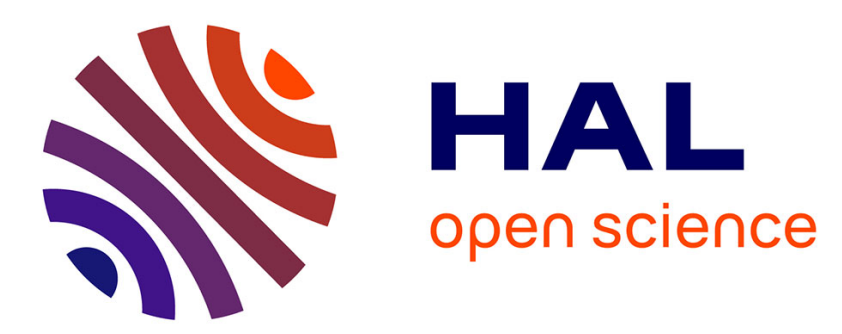

\title{
Effect of precipitation conditions on the morphology of strontium molybdate agglomerates
}

Ana Cameirão, René David, Fabienne Espitalier, Frédéric Gruy

\section{To cite this version:}

Ana Cameirão, René David, Fabienne Espitalier, Frédéric Gruy. Effect of precipitation conditions on the morphology of strontium molybdate agglomerates. Journal of Crystal Growth, 2008, 310 (18), pp.4152-4162. 10.1016/j.jcrysgro.2008.06.024 . emse-00500589

\section{HAL Id: emse-00500589 \\ https://hal-emse.ccsd.cnrs.fr/emse-00500589}

Submitted on 5 Sep 2018

HAL is a multi-disciplinary open access archive for the deposit and dissemination of scientific research documents, whether they are published or not. The documents may come from teaching and research institutions in France or abroad, or from public or private research centers.
L'archive ouverte pluridisciplinaire HAL, est destinée au dépôt et à la diffusion de documents scientifiques de niveau recherche, publiés ou non, émanant des établissements d'enseignement et de recherche français ou étrangers, des laboratoires publics ou privés. 


\title{
Effect of precipitation conditions on the morphology of strontium molybdate agglomerates
}

\author{
A. Cameirão ${ }^{\text {b,* }}$, R. David ${ }^{\text {a }}$, F. Espitalier ${ }^{\text {a }}$, F. Gruy ${ }^{\text {b }}$ \\ ${ }^{a}$ RAPSODEE Research Center/UMR CNRS 2392 Campus de Jarlard, 81013 Albi Cedex 09, France \\ ${ }^{\mathrm{b}}$ LPMG-UMR 5148, Ecole des Mines de St. Etienne, 158 Cours Fauriel, F-42023 Saint-Etienne Cedex 2, France
}

Preliminary experimental results about precipitation of strontium molybdate particles show that they have morphology as hierarchical agglomerates [A. Cameirão, R. David, F. Espitalier, F. Gruy, Multiple agglomeration in strontium molybdate precipitation, 16th ISIC, 2005, pp. 355-360]. The precipitation of strontium molybdate was studied and monitored in a batch reactor. The precipitation parameters, i.e. initial concentration of strontium molybdate, temperature and stirring rate, have an effect on the particles and agglomerates morphology. The shapes of the crystals were observed by SEM, and the PSD was measured at the end of precipitation by laser diffraction. The powders were also analysed by XRD, surface area (BET) and porosity measurements. Finally, a model of agglomeration was designed in order to predict the morphology of the observed agglomerates.

\section{Introduction}

Many industrial compounds obtained by precipitation, namely catalysts and pigments, present a structure of agglomerated crystals bonded by crystalline solid bridges. The common structure consists of crystallites with sizes between a few $\mathrm{nm}$ and $1 \mu \mathrm{m}$, which generate agglomerates of about $10 \mu \mathrm{m}$ (first degree of agglomeration), which in turn agglomerate to the final agglomerate sizes of about $100 \mu \mathrm{m}$ or sometimes up to $1 \mathrm{~mm}$ (second degree of agglomeration) (Fig. 1).

Strontium molybdate particles seem to have such morphology. Söhnel and Mullin [1] have observed that $\mathrm{SrMoO}_{4}$ precipitates are well-defined very compact crystals with neither formation of complexes in solution nor amorphous phase formation. The forming crystals quickly agglomerate during the entire crystallisation process.

\footnotetext{
* Corresponding author.

E-mail addresses: cameirao@emse.fr (A. Cameirão), rdavid@enstimac.fr (R. David), espitali@enstimac.fr (F. Espitalier), gruy@emse.fr (F. Gruy).
}

The induction time of precipitation is determined visually and it increases between 2 and $400 \mathrm{~s}$ at $25^{\circ} \mathrm{C}$ for decreasing concentrations of both reactants after mixing between 70 and $15 \mathrm{~mol} \mathrm{~m}^{-3}$. At the end of the induction time crystals are spherical. After $1 \mathrm{~min}$, they show an ellipsoidal shape of $8 \mu \mathrm{m}$ size and are all agglomerated after $30 \mathrm{~min}$ [1].

Söhnel and Mullin have concluded that increasing concentration increases the final size of particles; increasing stirring rate diminishes the size and induction time. Spheres seem to continue to grow after agglomeration. The final PSDs show sizes between 10 and $100 \mu \mathrm{m}[1]$.

This work presents the experimental results in order to understand and to model the dynamics of its precipitation. We have enlarged the work made by Söhnel and Mullin to a larger extent of concentrations and stirring rates, and we have introduced the study of the effect of temperature on the strontium molybdate precipitation. We have monitored the concentration during all precipitations in a way to model growth and nucleation and have characterised the most likely particles size distributions to understand and model the agglomeration process. 

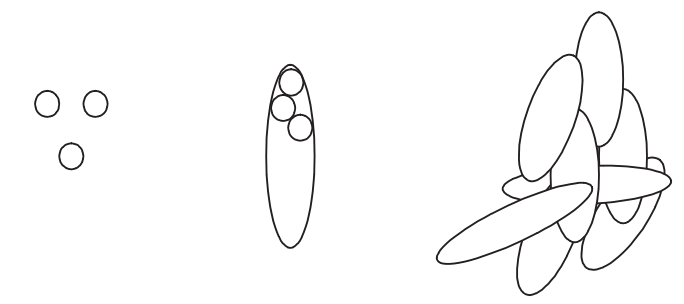

Crystallite Primary Agglomerate Secondary Agglomerate

Fig. 1. Agglomeration degrees.

\section{Experimental procedure}

\subsection{Materials}

In order to obtain $\mathrm{SrMoO}_{4}$, solutions of $\mathrm{Na}_{2} \mathrm{MoO}_{4}$ and $\mathrm{SrCl}_{2}$ (Sigma-Aldrich ${ }^{\circledR}$ ) were used. The precipitation obeys the chemical reaction

$\mathrm{SrCl}_{2(\mathrm{aq})}+\mathrm{Na}_{2} \mathrm{MoO}_{4(\mathrm{aq})} \rightarrow \mathrm{SrMoO}_{4(\mathrm{~s})} \downarrow+\mathrm{NaCl}_{(\mathrm{aq})}$

The solutions were prepared by dissolving the required amount of the analytical-grade chemicals, $\mathrm{SrCl}_{2}$ and $\mathrm{Na}_{2} \mathrm{MoO}_{4}$, in $1 \mathrm{~L}$ of deionised water. The precipitation was considered as completed $2 \mathrm{~h}$ after addition of reactants.

\subsection{Experimental apparatus}

The mixing of equimolar solutions of $\mathrm{Na}_{2} \mathrm{MoO}_{4}$ and $\mathrm{SrCl}_{2}$ was achieved in a $2 \mathrm{~L}$ glass crystalliser diameter $(15 \mathrm{~cm})$ with double jacket equipped with a three-bladed paddle stirrer [2] and four baffles, at a controlled temperature ranging between 10 and $80^{\circ} \mathrm{C}$. Initial concentration of strontium molybdate was varied between 4 and $100 \mathrm{~mol} \mathrm{~m}^{-3}$.

The Mixel ${ }^{\circledR}$ TT stirrer has a diameter of $50 \mathrm{~mm}$ and generates axial flow; the paddles are located at $120^{\circ}$ and inclined at $45^{\circ}$. It is powered by a motor Bioblock Scientific Digital 2000. The stirrer was placed at a clearance of $\frac{1}{3}$ of the height of the reactor from its bottom. A Rushton turbine was also used, which generates radial flow and higher turbulence in the discharge stream.

All experiments with changing concentration and temperature were made with the Mixel ${ }^{\mathbb{R}}$ TT. The calculated energy dissipation rate of the stirrer per unit mass ranged between $9 \times 10^{-4}$ and $1.5 \mathrm{~W} \mathrm{~kg}^{-1}(60-700 \mathrm{rpm})$. The stirrer Reynolds number was between $10^{3}$ and $10^{6}$, indicating mainly turbulent mixing regime.

\subsection{Procedures and methods}

\subsubsection{Characterisation of solution and particles}

The particle size distributions were measured by laser diffraction with a Malvern Master Sizer 2000 at the end of precipitation. We have observed that these measurements were reproducible when direct sampling of reactor suspension was made. Agglomerates were observed by SEM with a JSM 6400-Scanning Microscope after filtration of the suspension and drying at $40^{\circ} \mathrm{C}$.

Measurements of conductivity were also achieved on-line by using a conductometer (Consort 831, Bioblock). We verified that if the volume fraction of solids in suspension is lower than $0.5 \%$ particles do not interfere with conductivity measurements. Concentration of strontium molybdate was calculated from conductivity values [5].

The crystallite size was estimated by X-ray diffraction in a Siemens diffractometer D5000 Kristalloflex; the Hg-porosity was achieved in a Micromeritics-Auto Pore IV and the surface area measured by BET analysis in a Micromeritics_ASAP 2000.

\subsection{Preliminary studies}

We have made a preliminary study to settle the experimental protocol. We started with determining the minimum stirrer rate to suspend the particles. We have calculated this value by Zwietering's correlation [4] with a constant power number $\mathrm{Np}$ equal to 6 for a Rushton and 0.7 for a Mixel TT with a variable particle diameter $d_{\mathrm{p}}$ and a volume fraction of solid $\phi_{\mathrm{vs}}, g$ is the gravity; $\Delta \rho$ is the difference between the solid and the liquid density, $v$ is cinematic viscosity of the solution [4]. The minimal stirring rate depends on particles' concentration and size. From each experiment we measure the maximum size of particles. Thus, we can calculate $N_{\text {ms }}$ for each particle size by Zwietering [4] correlation.

We can deduce that the minimal stirring rate which fulfils the suspended solids condition is $350 \mathrm{rpm}$ for the Mixel stirrer and $125 \mathrm{rpm}$ for the Rushton.

Also, we have estimated the micromixing effects. Therefore, we have analysed the influence of the way of addition of the second reactive in the first one. We have concluded that there is negligible influence of micromixing in nucleation of strontium molybdate [2].

Each precipitation experiment was realised three times with the same operating conditions. The results for concentration against time and for final PSD were compared. The concentration values were equal within $15 \%$ error. The maximal error on volume percentage in each class of PSD is $1 \%$.

\subsection{Kolmogoroff and Batchelor microscales}

The Kolmogoroff microscale defined as

$l_{\mathrm{K}}=\left(\frac{v^{3}}{\varepsilon}\right)^{1 / 4}$

denotes the limit between laminar and turbulent regimes for fluid eddies.

The Batchelor microscale is the limit between the Brownian and laminar regimes for fluid eddies:

$\lambda_{\mathrm{B}}=\left(\frac{v D_{\mathrm{AB}}^{2}}{\varepsilon}\right)^{1 / 4}$

where $D_{\mathrm{AB}}$ is the diffusivity of a particle.

\section{Results}

\subsection{Change of supersaturation during precipitation}

The evolution of supersaturation ratio $\left(C / C^{*}\right)$ during precipitation is shown in Fig. 2 for several initial concentrations of $\mathrm{SrMoO}_{4}$ between 4 and $50 \mathrm{~mol} \mathrm{~m}^{-3}$. The solubility of $\mathrm{SrMoO}_{4}$ was measured by means of dissolution experiments at different temperatures and its expression was approximated by $C^{*}=$ $10^{-5} T^{2}+0.0015 T+0.0676[5]$.

The desupersaturation versus time is shown in Fig. 3 for temperatures between 25 and $50{ }^{\circ} \mathrm{C}$.

The desupersaturation versus time is plotted in Fig. 4 for various stirring rates and stirrer geometries. Note that the desupersaturation curve is very different between the two types of stirrers, which generate, even at the same energy dissipation rates, different patterns of flow and shear stresses. 


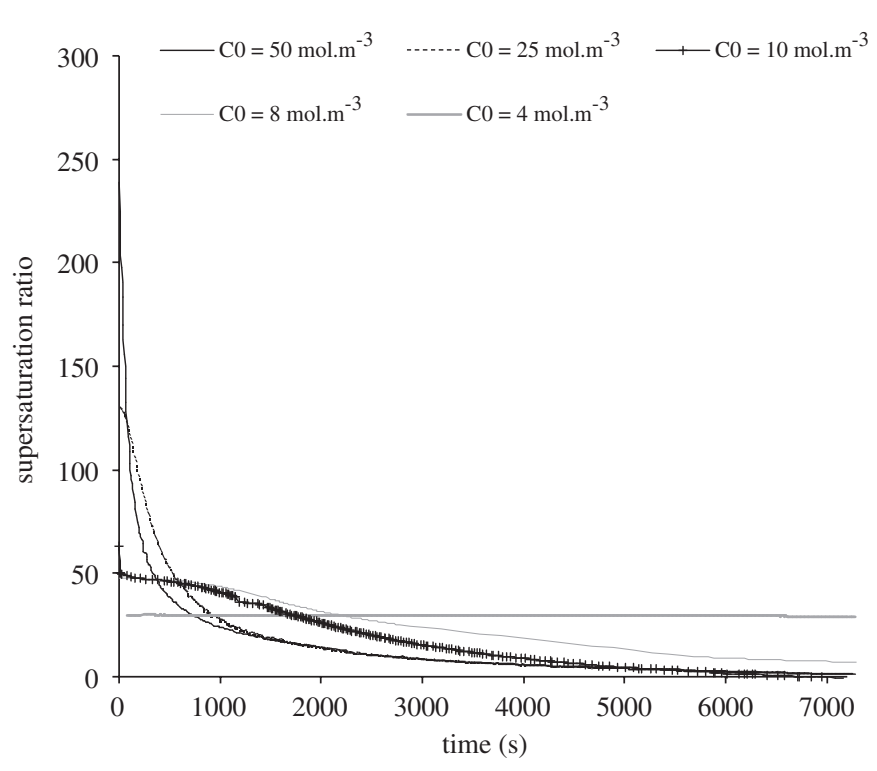

Fig. 2. Change of supersaturation ratio $\left(C / C^{*}\right)$ for different values of initial concentration $\left(25^{\circ} \mathrm{C}, 350 \mathrm{rpm}\right.$, Mixel $\left.{ }^{\mathbb{R}} \mathrm{TT}\right)$.

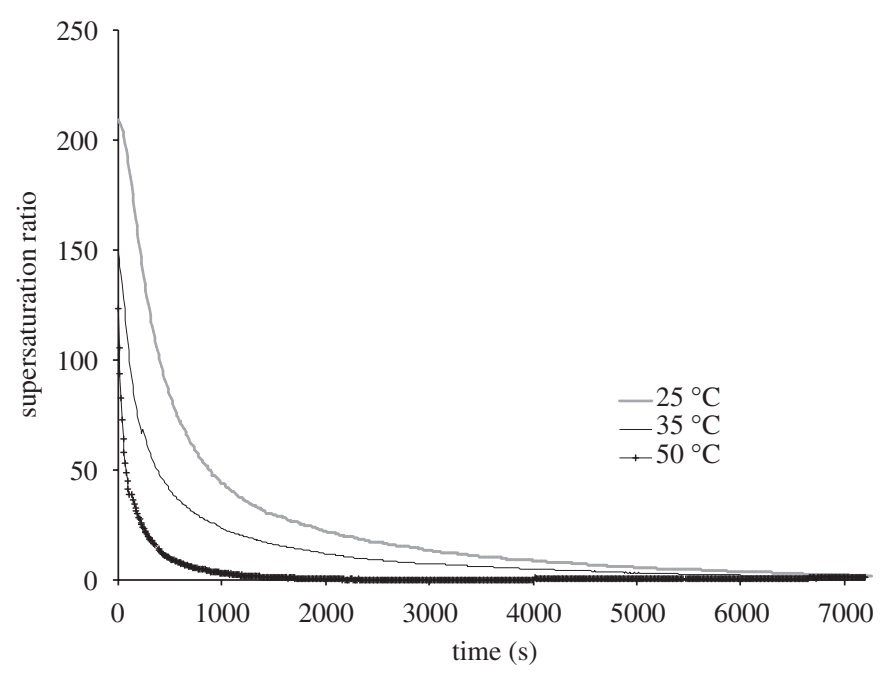

Fig. 3. Change of supersaturation ratio with time for different values of temperature $\left(C_{0}=25 \mathrm{~mol} \mathrm{~m}^{-3}, 350 \mathrm{rpm}\right.$, Mixel $\left.{ }^{\mathbb{\mathbb { R }}} \mathrm{TT}\right)$.

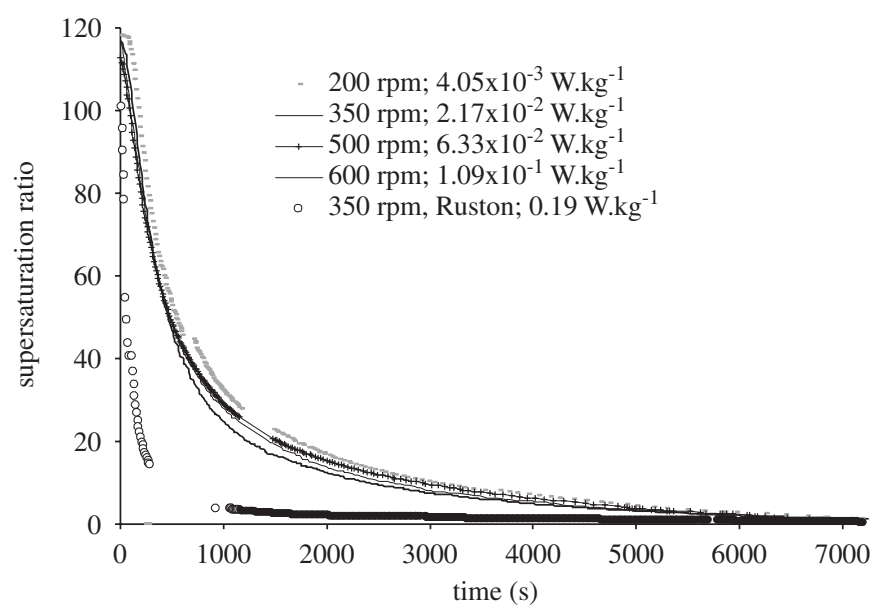

Fig. 4. Change of supersaturation ratio with time for different values of stirring rate and different stirrer geometries $\left(C_{0}=25 \mathrm{~mol} \mathrm{~m}^{-3}, 25^{\circ} \mathrm{C}\right)$.
Except for $C_{0}=4 \mathrm{~mol} \mathrm{~m}^{-3}$ precipitation appears to be almost finished after $6000 \mathrm{~s}$ of precipitation from conductivity measurements for all experiments.

With the Mixel stirrer, stirring rate does not affect the evolution of concentration of $\mathrm{SrMoO}_{4}$ in solution during precipitation (Fig. 4); thus a mixing speed $350 \mathrm{rpm}$ was fixed. The evolution of supersaturation ratio is mostly interesting in the cases when initial concentration and temperature are changed.

We observe that there is only a weak influence of stirring rate in desupersaturation ratio for a given impeller (Mixel ${ }^{\circledR} \mathrm{TT}$ ). This evidence suggests that there is no external diffusion limitation during crystal growth and that the surface integration process is the limiting one.

In order to demonstrate that crystal growth is limited by surface integration and not by external diffusion, we have calculated the Damkhöler number [6] for crystal growth.

The mass transfer coefficient is obtained from Mersmann [6]. First, we have to calculate the Reynolds number $\operatorname{Re}_{\mathrm{p}}$ (Eq. (3)) from specific power input $\varepsilon$ (at $350 \mathrm{rpm}$ ), maximum particle size $L$, power number $N_{\mathrm{p}}$, stirrer diameter $D_{\mathrm{a}}$ and cinematic viscosity $v$. We assume that viscosity is independent of concentrations:

$R e_{\mathrm{p}}=0.14\left(\frac{N_{\mathrm{p}} D_{\mathrm{a}}^{2}}{v}\right)^{0.133}\left(\frac{\varepsilon L^{2}}{v^{3}}\right)^{0.444}$

The mass transfer coefficient $k_{\mathrm{d}}$ for convection-diffusion is given by [10]

$\left.k_{\mathrm{d}}^{\prime}=\left(\frac{D_{\mathrm{AB}}}{L}\right) 2+0.6 R e_{\mathrm{p}}^{0.5}\left(\frac{v}{D_{\mathrm{AB}}}\right)^{0.33}\right)$

The diffusion growth coefficient $k_{\mathrm{d}}^{\prime}$ is given by

$k_{\mathrm{d}}=k_{\mathrm{d}}^{\prime} \frac{M_{\mathrm{SrMoO}_{4}} \phi_{\mathrm{s}}}{\rho_{\mathrm{c}} \phi_{\mathrm{v}}}$

The Damköhler number is derived from Eq. (6), assuming that the order of the surface integration process, $r$, is equal to 1 and a fraction of solid in the liquid $\omega$ reaches zero:

$D a=k_{\mathrm{r}}\left(c-c^{*}\right)^{\mathrm{r}-1}(1-\omega) k_{\mathrm{d}}^{-1}=k_{\mathrm{r}} k_{\mathrm{d}}^{-1}$

By using

$G=k_{\mathrm{r}}\left(c_{i}-c^{*}\right)=k_{\mathrm{d}}\left(c-c_{i}\right)$

we deduce the Damköhler's number:

$D a=\frac{G}{k_{\mathrm{d}}^{\prime}\left(c-c^{*}-\left(G / k_{\mathrm{d}}^{\prime}\right)\right)}$

The order of magnitude of the difference $c-c^{*}$ is considered as equal to the initial concentration of $\mathrm{SrMoO}_{4}$ divided by two.

For the precipitates with an order of the surface integration process equal to 1 and with fraction of solid in the liquid reaching zero, the effectiveness factor $\eta$ is given by Eq. (9) [2]. $\eta$ is the ratio between the actual growth rate and the growth rate limited by surface integration.

$\eta=\frac{1}{D a+1}$

We have determined the range of crystal growth rate $G$ from graphs of concentration against time during precipitation for several conditions. They belong to the interval between $1 \times 10^{-10}$ and $6 \times 10^{-8} \mathrm{~m} \mathrm{~s}^{-1}$. From these values we have determined $D a$ and the efficiency. The results are given in Table 1 .

Note that high growth rates $G$ are unlikely for small $C_{0}$ values, and low growth rates for high $C_{0}$ values as well. The results at these extreme concentrations are thus not exploited.

We observe that in most cases the effectiveness factor is close to 1 , except the one at high $G$ for $C_{0}=4 \mathrm{~mol} \mathrm{~m}^{-3}$. Generally, for the 
case of strontium molybdate precipitation we conclude that growth mainly is surface integration controlled.

\section{2. $\mathrm{SrMoO}_{4}$ powder characterisation}

\subsubsection{Morphology of particles by SEM}

The $\mathrm{SrMoO}_{4}$ particles obtained by precipitation were analysed in a way as to determine their agglomerate structure and sizes, their surface area and porosity.

3.2.1.1. Influence of stirring rate. First, the results of SEM micrographs for precipitates made under increasing stirring rate are presented.

For the same conditions of temperature and initial concentrations, the size and structure of the agglomerates look identical to both stirrers and at any stirring speed (Fig. 5).

3.2.1.2. Influence of initial supersaturation. Figs. 6-8 present the SEM micrographs of $\mathrm{SrMoO}_{4}$ for different initial concentrations of

\section{Table 1}

Damkhöler number and effectiveness factor for various initial concentration $C_{0}$ and $k_{\mathrm{d}}$ equal to $1.16 \times 10^{-4} \mathrm{~m} \mathrm{~s}^{-1}$ from $2.2\left(k_{\mathrm{d}}^{\prime}=3.81 \times 10^{-8} \mathrm{~m}^{4} \mathrm{~mol}^{-1} \mathrm{~s}^{-1}\right) .(350 \mathrm{rpm}$, Mixel $\left.{ }^{\mathbb{R}} \mathrm{TT}, 25^{\circ} \mathrm{C}\right)$

\begin{tabular}{lllll}
\hline$P(\mathrm{~W} / \mathrm{kg})$ & $G(\mathrm{~m} / \mathrm{s})$ & $C_{0}\left(\mathrm{~mol} \mathrm{~m}^{-3}\right)$ & $\mathrm{Da}$ & $\eta$ \\
\hline $2.2 \times 10^{-2}$ & $6.00 \times 10^{-8}$ & 100 & $1.3 \times 10^{-1}$ & 0.885 \\
& $1.00 \times 10^{-8}$ & 100 & $2.4 \times 10^{-2}$ & 0.976 \\
& $1.00 \times 10^{-8}$ & 4 & $3.8 \times 10^{-1}$ & 0.722 \\
& $1.00 \times 10^{-9}$ & 100 & $2.5 \times 10^{-3}$ & 0.998 \\
& $1.00 \times 10^{-9}$ & 4 & $5.9 \times 10^{-2}$ & 0.944 \\
& $1.00 \times 10^{-10}$ & 4 & $6.2 \times 10^{-3}$ & 0.994 \\
\hline
\end{tabular}

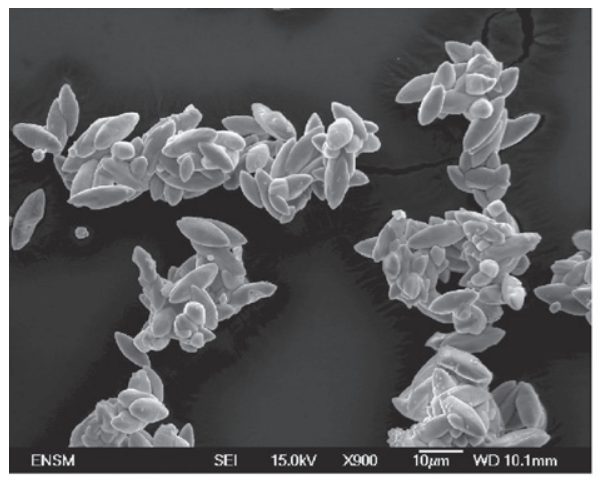

$200 \mathrm{rpm}$

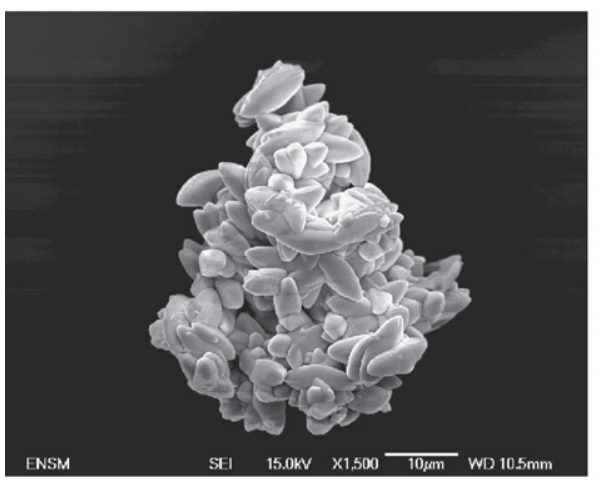

$600 \mathrm{rpm}$
$\mathrm{SrMoO}_{4}$ and for the same temperature and stirring rate, respectively, $25^{\circ} \mathrm{C}$ and $350 \mathrm{rpm}$.

Fig. 6 shows that, for low concentrations, the particles, which formed the agglomerates, are well crystallised in a bipyramidal shape.

Figs. 6-8 show that when increasing the initial concentration, the original particles that form the agglomerates increase in size and gradually change their shape from bipyramidal to ellipsoidal and become rod-like particles (for an initial concentration of $100 \mathrm{~mol} \mathrm{~m}^{-3}$ ). The agglomerates are also more porous at higher initial concentrations.

The transition from facetted crystals to non-facetted grains seems sharp and occurs for initial concentration of about $C_{0}=8.5 \pm 0.5 \mathrm{~mol} \mathrm{~m}^{-3}$ at $25^{\circ} \mathrm{C}$ (Fig. 7) [3].

The study of the influence of precipitation conditions on the strontium molybdate structure was used to determine the nucleation, growth and agglomeration mechanisms.

The initial concentration (supersaturation) of $\mathrm{SrMoO}_{4}$ is a major factor determining the structure of strontium molybdate powder.

We conclude from Fig. 8 that the first degree of agglomeration $(1-10 \mu \mathrm{m})$ has a changing morphology when $C_{0}$ increases.

For concentrations less than $8 \mathrm{~mol} \mathrm{~m}^{-3}$; we have formation of monocrystalline bipyramids with sizes between 5 and $6 \mu \mathrm{m}$ at the end of precipitation. When $C_{0}$ increases it becomes a polycrystalline grain with an ellipsoidal shape with sizes ranging from 10 to $12 \mu \mathrm{m}$. This change of shape can be a consequence of kinetic rough transition due to supersaturation changes [7].

Agglomerates $(20-100 \mu \mathrm{m})$ are very dense for low $C_{0}$ because piling-up of bipyramids is more easy (face to face). Increasing $C_{0}$ leads to more and more porous agglomerates.

The SEM micrographs show that for $C_{0} \geqslant 50 \mathrm{~mol} \mathrm{~m}^{-3}$ secondary agglomeration is weaker. At $100 \mathrm{~mol} \mathrm{~m}^{-3}$ this type of agglomeration has almost disappeared.

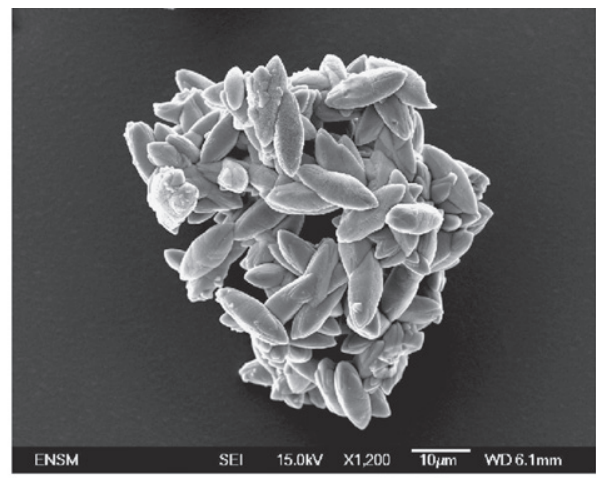

$350 \mathrm{rpm}$

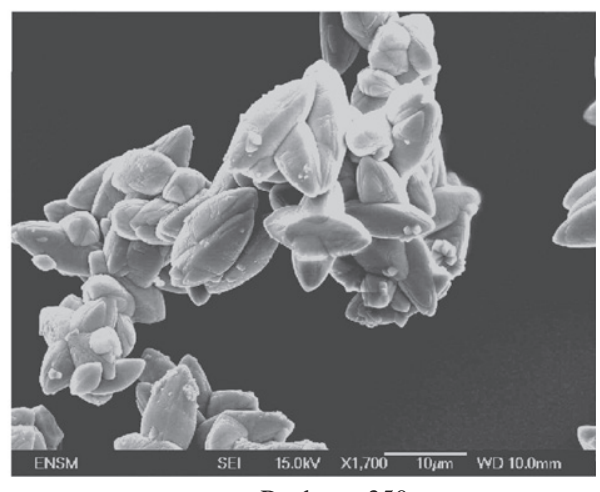

Rushton, $350 \mathrm{rpm}$

Fig. 5. SEM micrographs of $\mathrm{SrMoO}_{4}$ obtained at the end of precipitation with stirring speeds of $200,350,500$ and $600 \mathrm{rpm}^{\text {with a }} \mathrm{Mixel}^{\mathrm{\circledR}} \mathrm{TT}^{\mathrm{stirrer}}\left(25 \mathrm{~mol} \mathrm{~m}^{-3}, 25^{\circ} \mathrm{C}\right)$. 


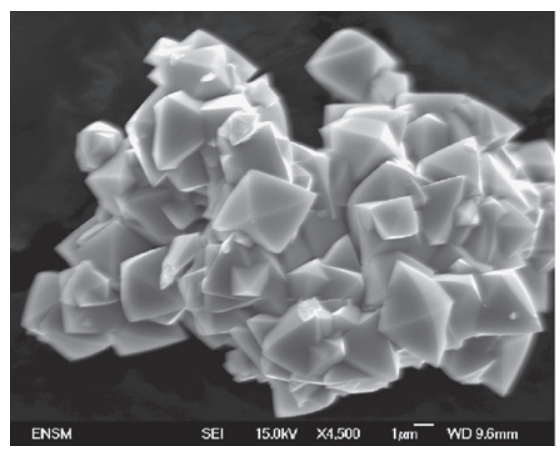

4 mol.m $\mathrm{m}^{-3}$

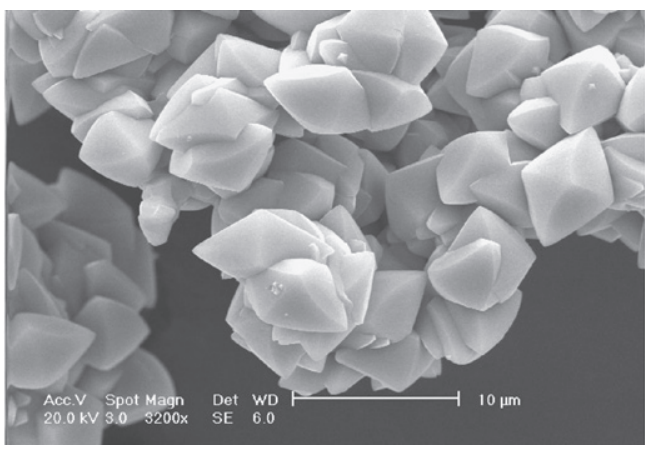

$8 \mathrm{~mol} . \mathrm{m}^{-3}$

Fig. 6. SEM micrographs of $\mathrm{SrMoO}_{4}$ obtained at the end of precipitation with initial concentrations of 4 and $8 \mathrm{~mol} \mathrm{~m}^{-3}\left(25^{\circ} \mathrm{C}, 350 \mathrm{rpm}\right.$, Mixel ${ }^{\circledR} \mathrm{TT}^{\mathrm{s}}$ stirrer).

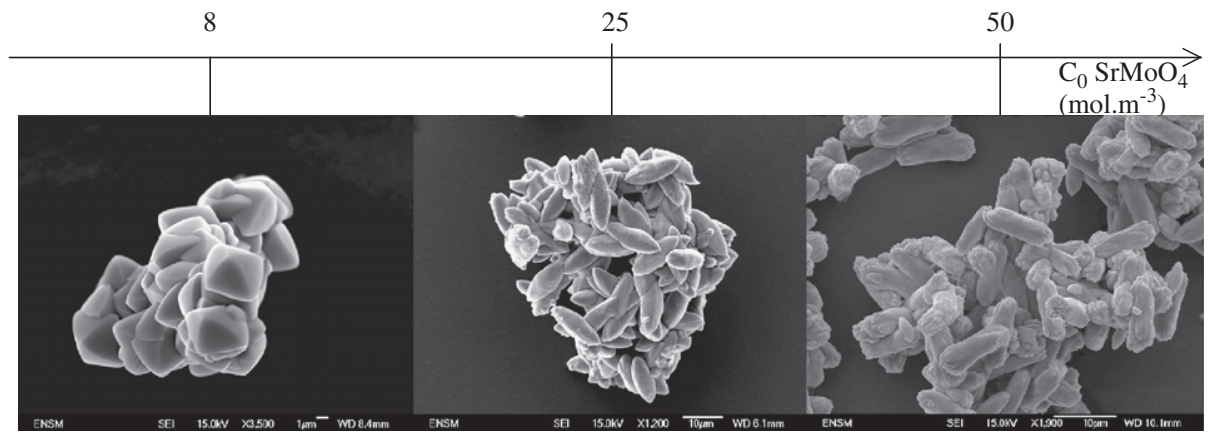

Fig. 7. Morphology of agglomerates at various $C_{0}\left(25^{\circ} \mathrm{C}\right.$, Mixel ${ }^{\circledR}$ TT stirrer, $\left.350 \mathrm{rpm}\right)$.
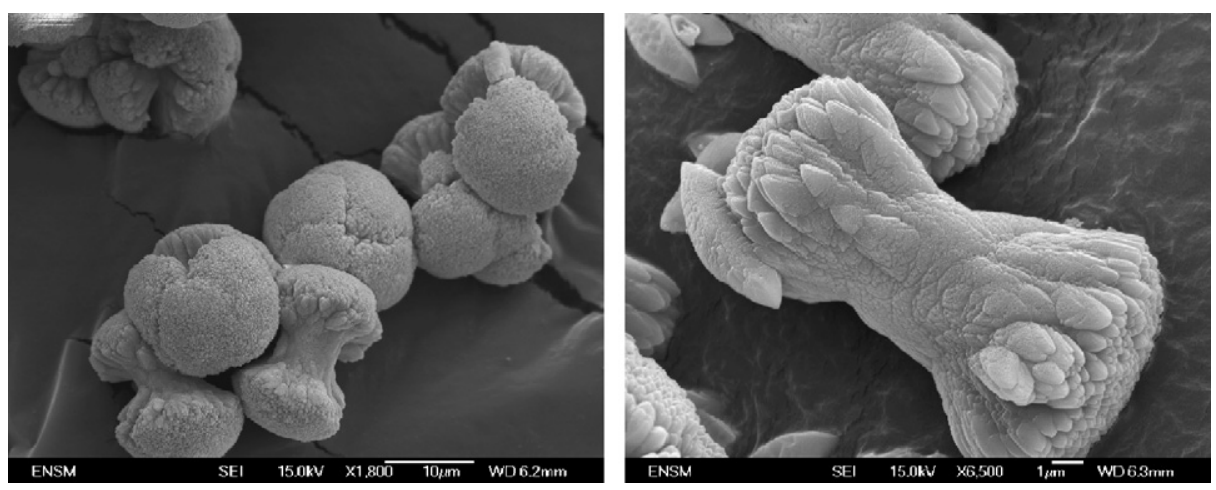

Fig. 8. SEM micrographs of $\mathrm{SrMoO}_{4}$ obtained at the end of precipitation with initial concentration of $100 \mathrm{~mol} \mathrm{~m}^{-3}\left(T=25^{\circ} \mathrm{C}, 350 \mathrm{rpm}, \mathrm{Mixel}^{\mathbb{1}} \mathrm{TT}\right.$ stirrer).

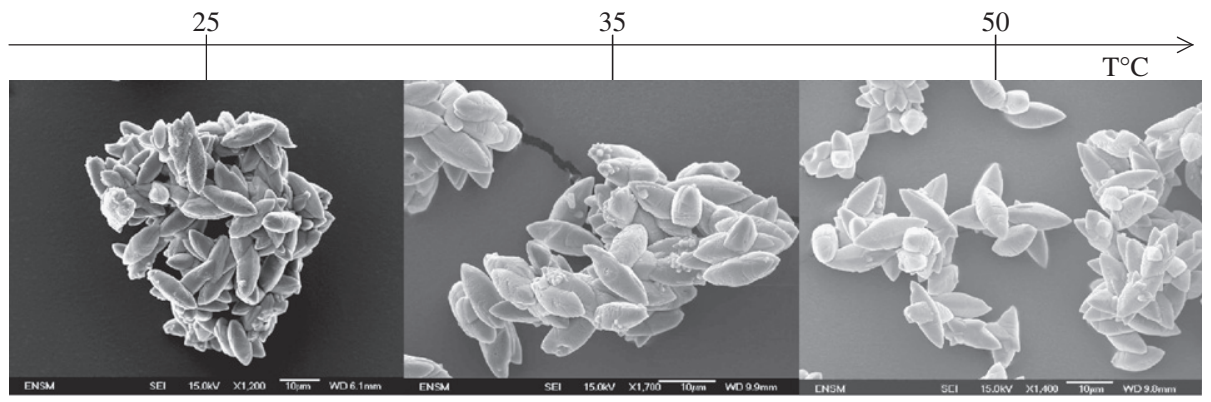

Fig. 9. Morphology of agglomerates at various temperatures $\left(25 \mathrm{~mol} \mathrm{~m}^{-3}\right.$, Mixel ${ }^{\mathbb{R}}$ TT stirrer, $\left.350 \mathrm{rpm}\right)$.

3.2.1.3. Influence of temperature. Fig. 9 shows the structure of agglomerates for initial concentration of $\mathrm{SrMoO}_{4}$ equal to $25 \mathrm{~mol} \mathrm{~m}^{-3}$ and a stirring rate $350 \mathrm{rpm}$ at various temperatures.

The particles have an ellipsoidal shape with sizes from 8 to $15 \mu \mathrm{m}$. Particles have an ellipsoidal shape at temperatures below $80^{\circ} \mathrm{C}$, but when the temperature increases these particles have an increasing size and they show a bipyramidal shape rather than ellipsoidal: particles are more peaky at the ends and with a smoother surface.

Agglomerates have a size between 30 and $60 \mu \mathrm{m}$ at the end of precipitation at various temperatures. Agglomerates formed at 
low temperature are denser than those formed at low supersaturation (higher temperature) even if their shape is different: the agglomeration degree is enhanced by low temperatures (Fig. 9).

\subsubsection{Particle and pore size distributions}

3.2.1.4.1. Influence of stirring rate. In Fig. 10, for the same temperature and $C_{0}$ the PSD is shifted toward the larger particles when the stirring rate increases.

Fig. 11 shows that the pore size decreases as the energy dissipation increases. The pore sizes less than $10 \mu \mathrm{m}$ are located between primary agglomerates. These pores are also observed in the SEM micrographs. The pores sizes greater than $10 \mu \mathrm{m}$ are located between secondary agglomerates. We conclude from pore size distributions and from SEM micrographs that the primary particles do not have internal porosity.

It can be seen that with increasing energy dissipation we have decreasing size of particles and increasing pore size, because the

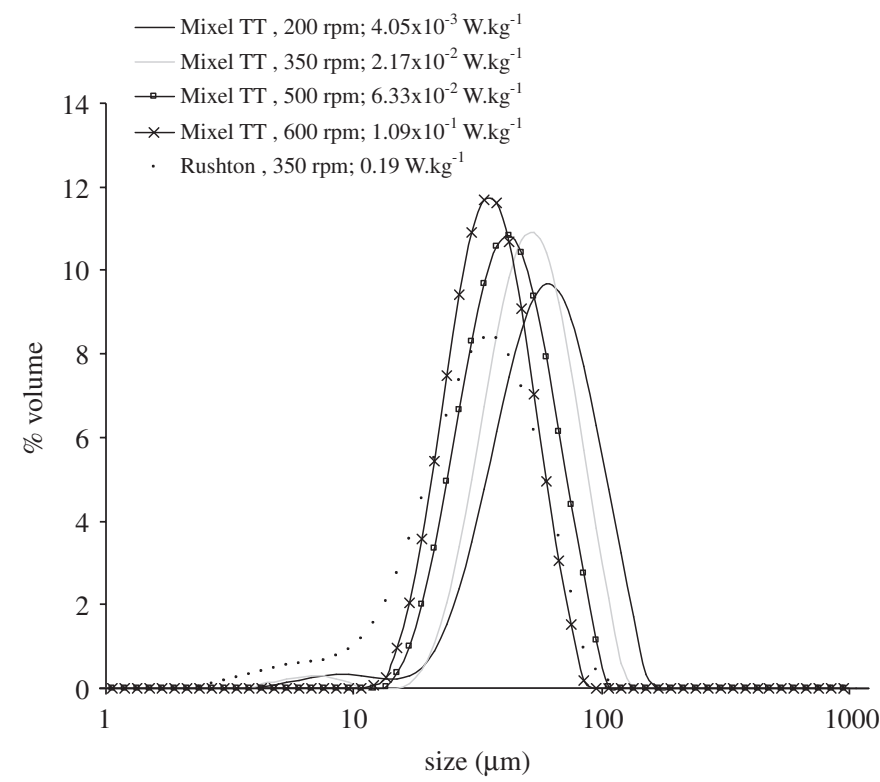

Fig. 10. PSD of $\mathrm{SrMoO}_{4}$ particles at the end of precipitation for different stirring rates and stirrers $\left(25 \mathrm{~mol} \mathrm{~m}^{-3}, 25^{\circ} \mathrm{C}\right)$. size of agglomerates is limited by the Kolmogoroff micro-scale. Observations of the SEM micrographs in Fig. 5 do not confirm this trend. As far as large particle sizes are considered, the use of a Rushton turbine at $350 \mathrm{rpm}$ results in a PSD which is quite similar to that obtained with a Mixel stirrer at $600 \mathrm{rpm}$ (same energy dissipation rates). But, at smaller and medium sizes, the Rushton turbine inhibits agglomeration. A substantial difference in the agglomerate porosity is also noted between both stirrers.

3.2.1.4.2. Influence of initial concentrations. The PSDs in Fig. 12 for the same stirrer speed, and $C_{0}$ between 2 and $100 \mathrm{~mol} \mathrm{~m}^{-3}$ are relatively close to each other. They present a larger peak between 10 and $100 \mu \mathrm{m}$ and a smaller peak between 1 and $10 \mu \mathrm{m}$. Increasing $C_{0}$ increases the average size and skews the larger peak.

Fig. 13 shows with increasing $C_{0}$ decreasing maximum pore size and decreasing pore sizes of the maximum peak. For $8 \mathrm{~mol} \mathrm{~m}^{-3}$ only large pores are observed: the average pore size is equal to $30 \mu \mathrm{m}$. The bipyramids formed with this lower concentration are very closely-piled to form secondary agglomerates, and so they lack internal porosity. It can be concluded that the pores greater than $10 \mu \mathrm{m}$ are the pores between secondary agglomerates observed by SEM pictures (Figs. 6-8).

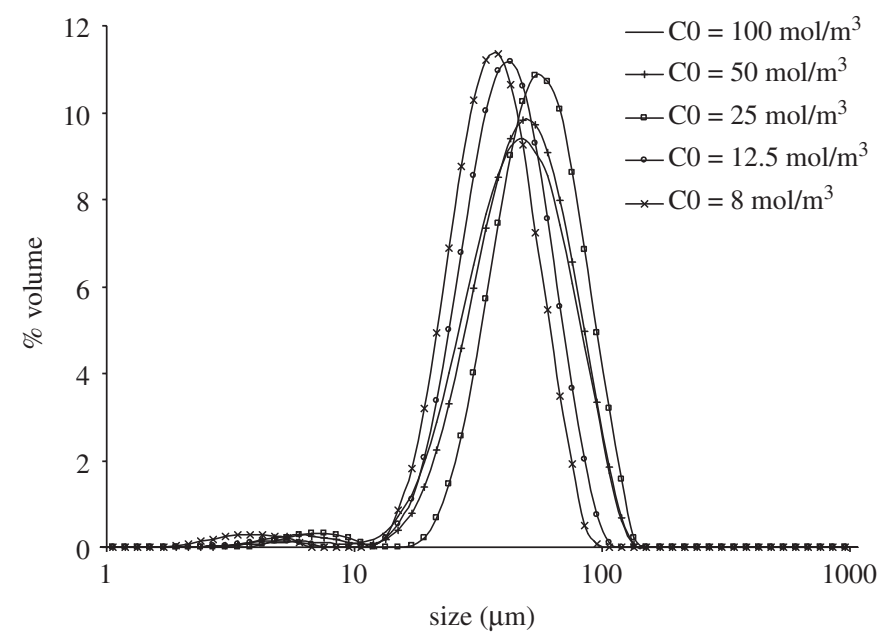

Fig. 12. PSD distributions of $\mathrm{SrMoO}_{4}$ at the end of precipitation at different $C_{0}$ (Mixel ${ }^{\mathbb{R}}$ TT, $350 \mathrm{rpm}, 25^{\circ} \mathrm{C}$ ).

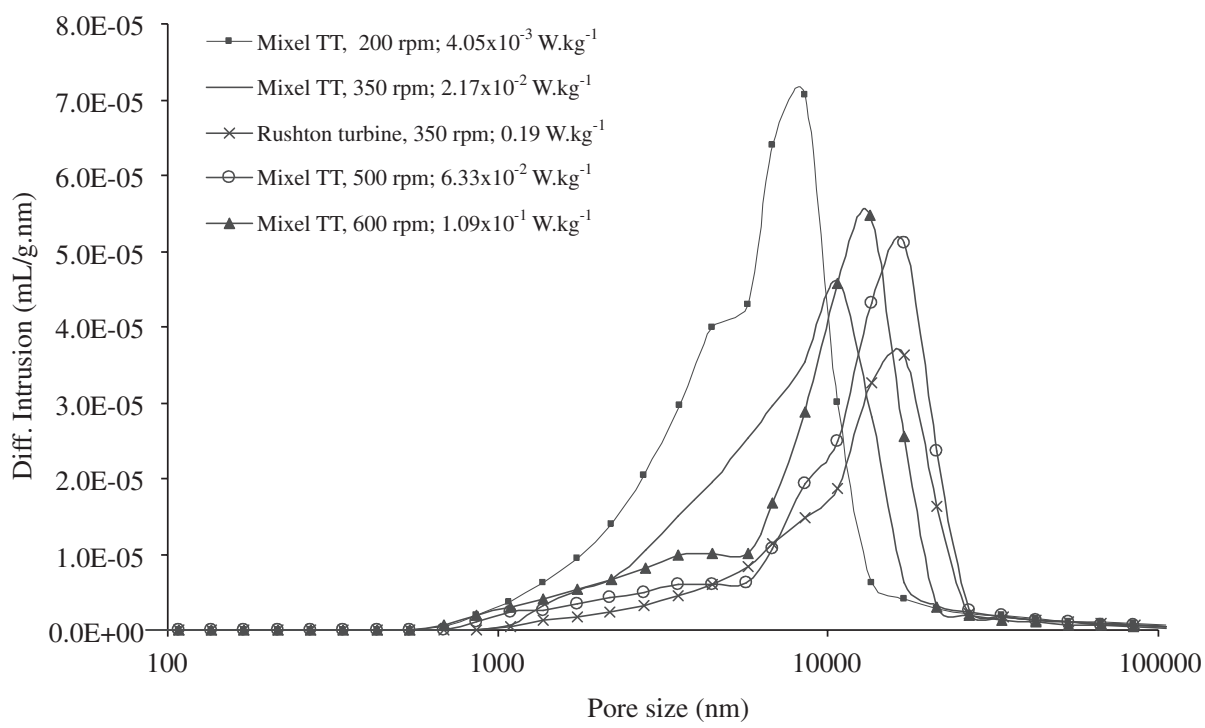

Fig. 11. Pore size distributions of $\mathrm{SrMoO}_{4}$ at the end of precipitation for different stirring rates and stirrers $\left(25 \mathrm{~mol} \mathrm{~m}^{-3}, 25^{\circ} \mathrm{C}\right)$. 


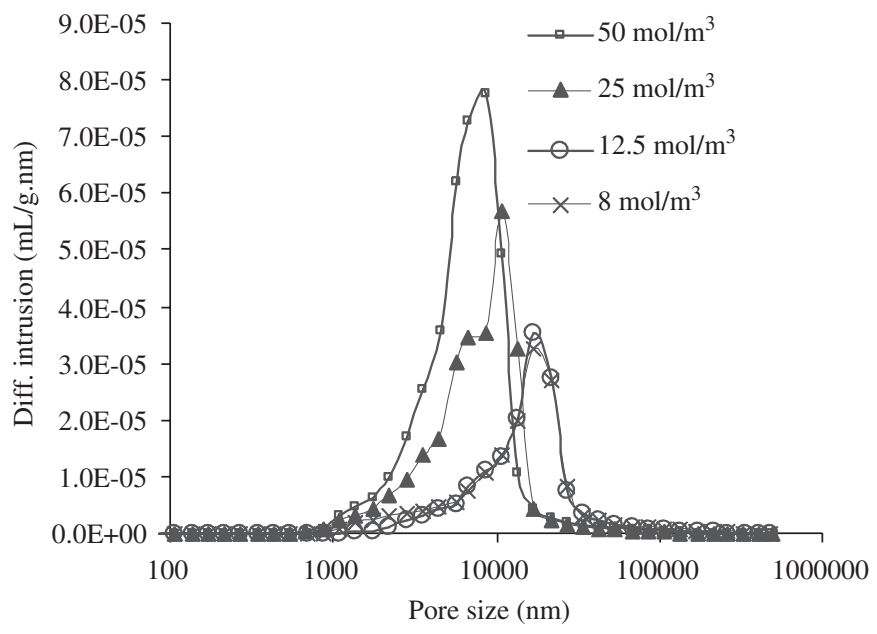

Fig. 13. Pore size distributions of $\mathrm{SrMoO}_{4}$ at the end of precipitation at different $C_{0}$ (Mixel ${ }^{\mathbb{R}}$ TT, $350 \mathrm{rpm}, 25^{\circ} \mathrm{C}$ ).

The pore size distributions and the SEM micrographs allow to conclude that bipyramids and ellipsoids do not have internal porosity. The internal porosity of cylinders is not visible in the pore size distributions at $50 \mathrm{~mol} \mathrm{~m}^{-3}$.

For 25 and $50 \mathrm{~mol} \mathrm{~m}^{-3}$, the pore size is less than $10 \mu \mathrm{m}$ because the ellipsoids are not so closely piled: so, secondary agglomerates are less compacted. The pore average sizes at these concentrations are 10 and $8.6 \mu \mathrm{m}$, respectively.

The agglomerates at $50 \mathrm{~mol} \mathrm{~m}^{-3}$ present a wider pore size distribution and a large porous volume because these agglomerates are more porous than agglomerates for small concentrations. It seems that both the agglomeration mechanism and the efficiency change with $C_{0}$.

3.2.1.4.3. Influence of temperature. In Fig. 14 for $C_{0}$ equal to $25 \mathrm{~mol} \mathrm{~m}^{-3}$ and a stirring rate equal to $350 \mathrm{rpm}$ the average size $d_{43}$ of PSD increases with decreasing temperatures.

We can see that with increasing temperature we have a larger size of particles (bipyramids/ellipsoids and agglomerates).

The PSD presents the same kind of profile with two populations, one peak for sizes less than $10 \mu \mathrm{m}$ and another heavier one for sizes between 10 and $100 \mu \mathrm{m}$. With decreasing temperature the peak goes for larger sizes and spreads out.

It seems that there is an effect of temperature on nucleation and growth and also on agglomeration. The two agglomeration regimes and the growth rates are temperature dependent. However, the temperature mostly affects the growth rate constant. At $80^{\circ} \mathrm{C}$, we have formation of ellipsoids with a size of $20 \mu \mathrm{m}$ and consolidation, which are the first consumers of supersaturation.

We have less secondary agglomeration at the highest temperatures, i.e. 50 and $80^{\circ} \mathrm{C}$, and two explanations can be proposed:

- Enough crystalline material for strengthening the secondary agglomerates does not remain in the solution.

- The formation of secondary agglomeration of sizes higher than $20 \mu \mathrm{m}$ diminishes because they are close to the Kolmogoroff microscale of $37 \mu \mathrm{m}$.

We can observe in pore size distributions obtained from experiment that the increase in temperature does not affect the pore size; these results are shown in a previous work [5].

3.2.1.4.4. Agglomerate size versus Kolmogoroff microscale. In order to study the relation between hydrodynamics and agglom-

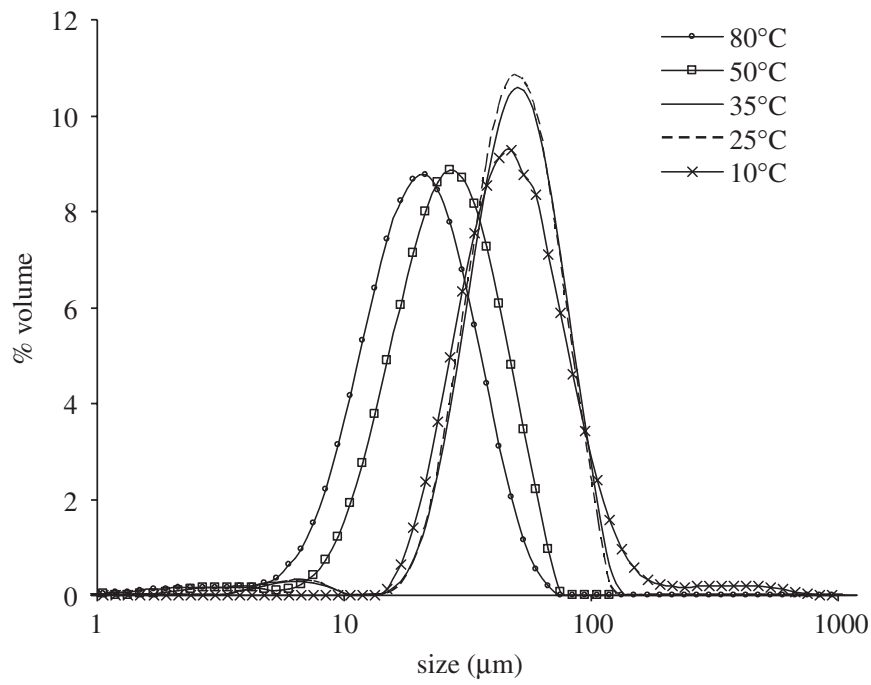

Fig. 14. PSD distributions of $\mathrm{SrMoO}_{4}$ at the end of precipitation at various temperatures (Mixel ${ }^{\mathbb{R}}$ TT, $350 \mathrm{rpm}, 25 \mathrm{~mol} \mathrm{~m}^{-3}$ ).

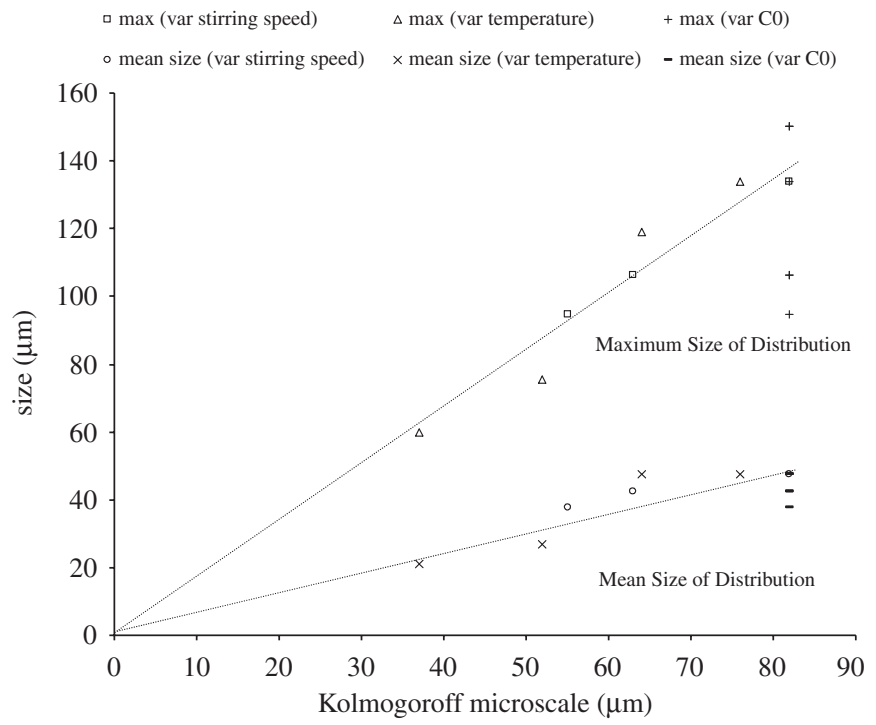

Fig. 15. Maximum and average sizes versus Kolmogoroff microscale.

eration sizes, we have plotted the maximum and average size obtained from PSD vs. the Kolmogoroff microscale.

Whatever the stirring speed, the stirrer type or the temperature, the data show linear dependencies of the maximum and average sizes on $l_{\mathrm{K}}$.

From Fig. 15, we can see that the dependency of mean size on Kolmogoroff microscale has a slope less than 1 . We can conclude that almost all agglomeration of strontium molybdate particles takes place in the viscous (laminar) range of turbulence.

We also see that the slope of maximum size against Kolmogoroff microscale is slightly higher than one. But particles larger than the Kolmogoroff microscale never appear in SEM micrographs and PSDs: we can thus conclude that they are not statistically significant, which is coherent with the above conclusion. It could also be related to an artefact of the PSD measurement.

3.2.1.4.5. Size of crystallites. The $\mathrm{SrMoO}_{4}$ powder was studied by XRD and crystallite size (or a size proportional to crystallites size) was calculated by Scherrer's law. The results for precipitations at various stirring rates and temperatures are shown in Table 2 and they all resulted in about the same crystallite size. 
Table 2

Crystallites size of $\mathrm{SrMoO}_{4}$ determined by XRD for different stirring rate and temperature (Mixel stirrer, $25 \mathrm{~mol} \mathrm{~m}^{-3}$ )

\begin{tabular}{ll}
\hline & Crystallite size $(\mathrm{nm})$ \\
\hline $\begin{array}{l}\text { Stirring rate }(\mathrm{rpm}) \\
350\end{array}$ & $157( \pm 40)$ \\
600 & $155( \pm 36)$ \\
& \\
Temperature $\left({ }^{\circ} \mathrm{C}\right)$ & $157( \pm 40)$ \\
25 & $113( \pm 36)$ \\
35 & $157( \pm 52)$ \\
50 & \\
\hline
\end{tabular}

Table 3

Crystallites size of $\mathrm{SrMoO}_{4}$ determined by RXD for different initial concentration

\begin{tabular}{lll}
\hline $\begin{array}{l}\text { Concentration } \\
\left(\mathrm{mol} \mathrm{m}^{-3}\right)\end{array}$ & Morphology & $\begin{array}{l}\text { Crystallite } \\
\text { size }(\mathrm{nm})\end{array}$ \\
\hline 8 & Bipyramidal & 140 \\
9 & Ellipsoidal & 147 \\
10 & Ellipsoidal & 172 \\
12.5 & Ellipsoidal & $280( \pm 17)$ \\
25 & Ellipsoidal & $157( \pm 40)$ \\
50 & Cylindrical & $92( \pm 16)$ \\
\hline
\end{tabular}

The results for different initial supersaturation or concentration are shown in Table 3. The size of crystallites depends on the nucleation and growth rates and thus on initial concentrations. We can see that there are two different domains of evolution that correspond to the two shapes (bipyramids or ellipsoids) of precipitates. In the first domain (bipyramidal particles) we have increasing crystallite size with supersaturation. In the second domain for ellipsoidal particles we have decreasing crystallite size with supersaturation.

3.2.1.4.6. Surface area. The surface area of the $\mathrm{SrMoO}_{4}$ powder was determined by BET, and the results (Table 4) show that increasing $C_{0}$ increases the external surface. The theoretical specific areas of the samples were calculated from SEM micrographs assuming bipyramidal, ellipsoidal or cylindrical shapes (Fig. 16), respectively, and from observed sizes. The differences between theoretical and experimental values are due to the existence of contacts between grains that are not included in the theoretical calculation. Primary particles of bipyramidal shape do not show any porosity.

\subsection{Evidence for kinetic roughening}

In 1951, Burton, Cabrera and Franck have described the crystal growth and the structure of the equilibrium surfaces using the Ising model [12]. The interface between crystal and vacuum can have a phase transition order-disorder known as rough transition defined by a roughening temperature $T^{R}$ : growth at temperatures less than $T^{\mathrm{R}}$ made crystal surfaces flat, whereas for temperatures higher than $T^{\mathrm{R}}$ crystal surfaces are rough.

Grimbergen showed that when a solid-liquid system is far from being in equilibrium, i.e. with larger supersaturation, the surface can become rough even if its temperature is less than $T^{R}$; this is known as a kinetic rough transition [8].

In order to obtain the solubility of the $\mathrm{SrMoO}_{4}$ in water at different temperatures, we achieved a set of experiments by dissolution. We have dissolved the powder of $\mathrm{SrMoO}_{4}$ in water in a thermostated vessel at a given temperature during for several hours. After dissolution the powder remaining in the suspension was filtered and observed by SEM. The SEM micrographs obtained are shown in Fig. 17.
Table 4

Experimental results of BET specific area of the $\mathrm{SrMoO}_{4}$ for different stirring rates and theoretical surfaces calculated as functions of particle geometry $\left(25 \mathrm{~mol} \mathrm{~m}^{3}\right.$, $25^{\circ} \mathrm{C}, 350 \mathrm{rpm}$ )

\begin{tabular}{|c|c|c|c|c|}
\hline & $\begin{array}{l}A_{\text {spec }}\left(\mathrm{m}^{2} / \mathrm{g}\right) \\
\text { experimental }\end{array}$ & $\begin{array}{l}A_{\text {spec }}\left(\mathrm{m}^{2} / \mathrm{g}\right) \\
\text { theoretical }\end{array}$ & $\begin{array}{l}\text { Particle } \\
\text { geometry }\end{array}$ & $\begin{array}{l}\text { Shape/Size } \\
\text { parameters } \\
\left(L^{\mathrm{a}}, a^{\mathrm{b}}\right) \mu \mathrm{m}\end{array}$ \\
\hline \multicolumn{5}{|c|}{ Stirring rate (rpm) } \\
\hline 200 & 0.24 & 0.28 & Ellipsoid & $L=12 ; a=5$ \\
\hline 350 & $0.20( \pm 0.003)$ & 0.28 & Ellipsoid & $L=12 ; a=5$ \\
\hline 500 & 0.18 & 0.28 & Ellipsoid & $L=12 ; a=5$ \\
\hline 600 & 0.19 & 0.28 & Ellipsoid & $L=12 ; a=5$ \\
\hline \multicolumn{5}{|c|}{$C_{0}\left(\mathrm{~mol} \mathrm{~m}^{-3}\right)$} \\
\hline 8 & $0.13( \pm 0.002)$ & 0.74 & Bipyramid & $L=8 ; a=4$ \\
\hline 9 & $0.200( \pm 0.002)$ & 0.28 & Ellipsoid & $L=8 ; a=4$ \\
\hline 10 & $0.210( \pm 0.003)$ & 0.28 & Ellipsoid & $L=8 ; a=4$ \\
\hline 12.5 & $0.120( \pm 0.003)$ & 0.28 & Ellipsoid & $L=8 ; a=4$ \\
\hline 25 & $0.21( \pm 0.003)$ & 0.28 & Ellipsoid & $L=12 ; a=5$ \\
\hline 50 & $0.41( \pm 0.009)$ & 0.41 & Cylinder & $\begin{array}{l}L=12 \\
a=3.2 \\
n^{\mathrm{c}}=6 \\
r^{\mathrm{d}}=1\end{array}$ \\
\hline \multicolumn{5}{|l|}{$T\left({ }^{\circ} \mathrm{C}\right)$} \\
\hline 10 & $0.18( \pm 0.0013)$ & & & \\
\hline 25 & $0.20( \pm 0.003)$ & 0.28 & Ellipsoid & $L=12 ; a=5$ \\
\hline 35 & $0.81( \pm 0.003)$ & 0.28 & Ellipsoid & $L=12 ; a=5$ \\
\hline 50 & $0.158( \pm 0.0013)$ & 0.28 & Ellipsoid & $L=12 ; a=5$ \\
\hline 80 & $0.33( \pm 0.0027)$ & 0.28 & Ellipsoid & $L=12 ; a=5$ \\
\hline
\end{tabular}

\footnotetext{
a length of the grain.

b width of the grain.

${ }^{c}$ number of cylinders.

${ }^{\mathrm{d}}$ radius $=$ cylinder height.
}

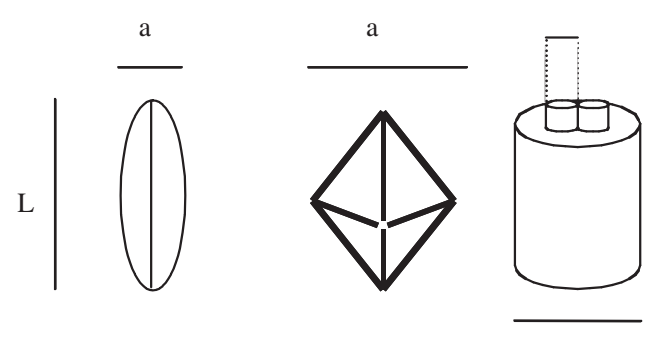

a

Fig. 16. Geometric shapes to calculate specific area.

The ellipsoidal particles after dissolution presented a significant open porosity.

\subsection{Seeding experiments}

We have studied the stability of the forms bipyramids and ellipsoids synthesised at $C_{0}=8 \mathrm{~mol} \mathrm{~m}^{-3}$ and at $25 \mathrm{~mol} \mathrm{~m}^{-3}$ using them as seeds at $C_{0}=25 \mathrm{~mol} \mathrm{~m}^{-3}$ and at $C_{0}=8 \mathrm{~mol} \mathrm{~m}^{-3}$, respectively.

Thus, we have made a precipitation as explained in Sections 2.1 and 2.2 at $C_{0}=8 \mathrm{~mol} \mathrm{~m}^{-3}$, but adding ellipsoidal seeds from a previous experiment at $C_{0}=25 \mathrm{~mol} \mathrm{~m}^{-3}$. Another experiment was done at $C_{0}=25 \mathrm{~mol} \mathrm{~m}^{-3}$ adding seeds from the experiment at $C_{0}=8 \mathrm{~mol} \mathrm{~m}^{-3}$. The weight of seeds was equal to $6.5 \%$ of the solid mass at the end of precipitation at $C_{0}=25 \mathrm{~mol} \mathrm{~m}^{-3}$ and $3 \%$ at $C_{0}=8 \mathrm{~mol} \mathrm{~m}^{-3}$. With these two experiments, we tried to find if bipyramids transform into ellipsoids and if the ellipsoidal form is stable at lower concentrations. At the end of each experiment we characterised the powder by laser diffraction and SEM micrographs. The latter are especially interesting. 

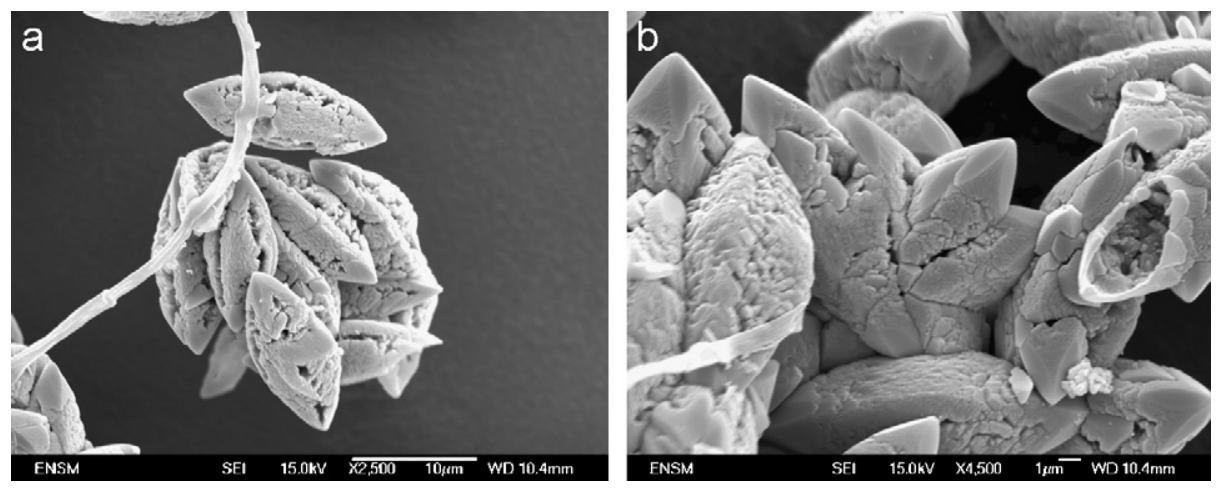

Fig. 17. SEM micrographs of $\mathrm{SrMoO}_{4}$ after dissolution at $30^{\circ} \mathrm{C}$ (a) and $70^{\circ} \mathrm{C}$ (b) respectively during $24 \mathrm{~h}$.
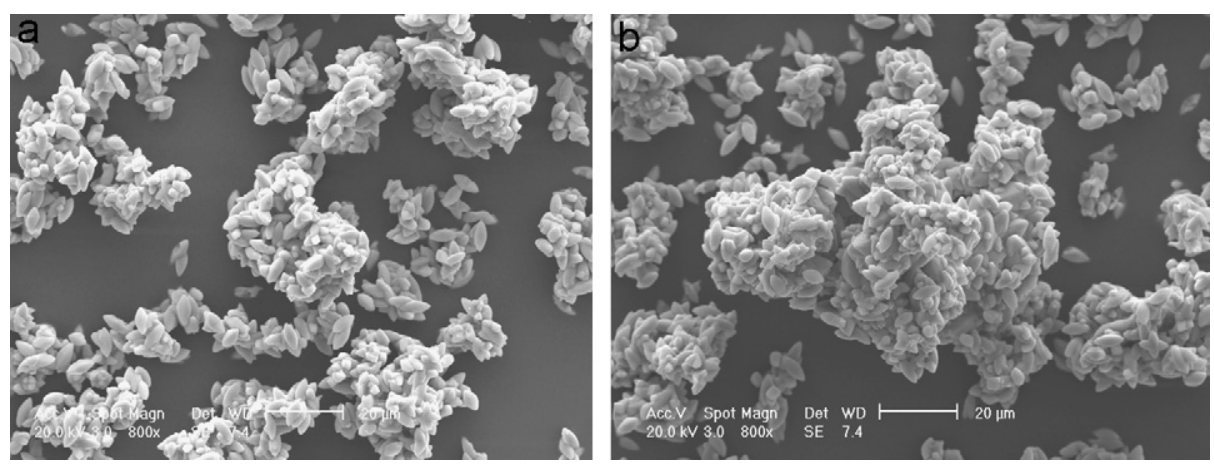

Fig. 18. SEM micrograph of $\mathrm{SrMoO}_{4}$ at the end of precipitation at $C_{0}=25 \mathrm{~mol} \mathrm{~m}^{-3}, 25{ }^{\circ} \mathrm{C}$ and $350 \mathrm{rpm}$ with a Mixel TT ${ }^{\mathbb{B}}$ using bipyramidal seeds.
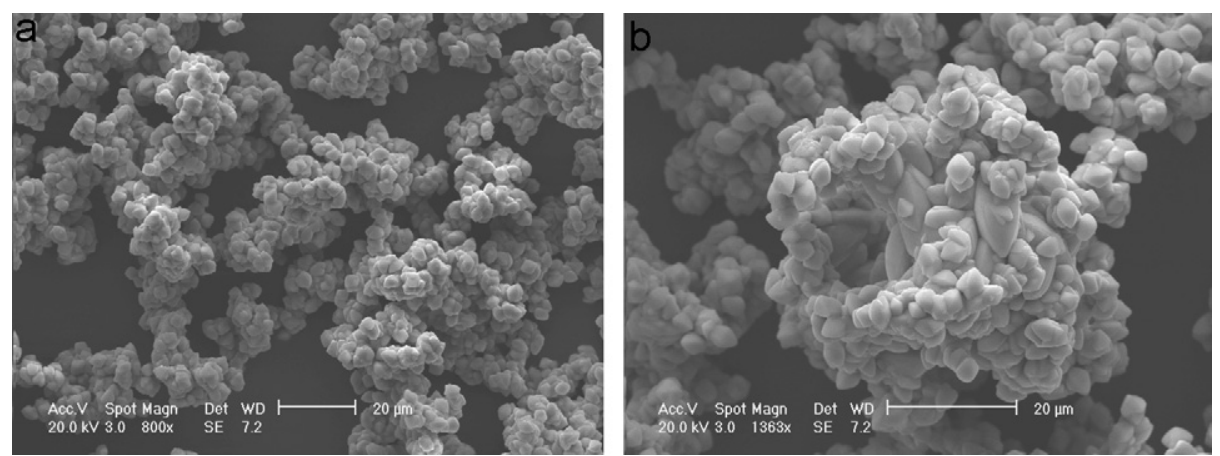

Fig. 19. SEM micrograph of $\mathrm{SrMoO}_{4}$ at the end of precipitation at $C_{0}=25 \mathrm{~mol} \mathrm{~m}^{-3}, 25^{\circ} \mathrm{C}$ and 350 rpm with a Mixel $\mathrm{TT}^{\mathbb{B}}$ using bipyramidal seeds.

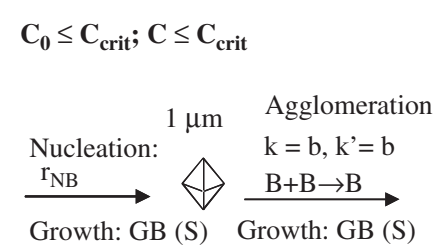

Monocrystal

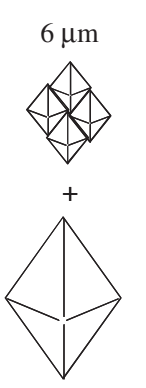

Monocrystal

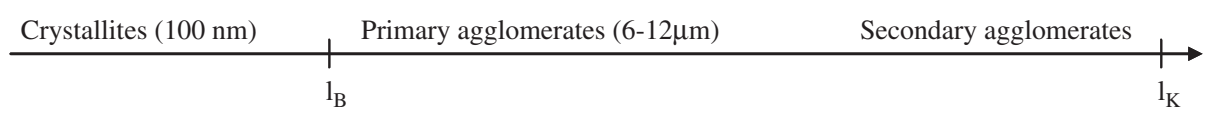

Fig. 20. Precipitation processes for $C_{0}<C_{\text {crit }}$ (legend: $k=$ collision hydrodynamics, $k^{\prime}=$ consolidation hydrodynamics, $b=$ Brownian regime, $l=$ laminar regime). 
The precipitations using bipyramidal seeds at $C_{0}=25 \mathrm{~mol} \mathrm{~m}^{-3}$ show (Fig. 18a) the same mechanism of nucleation, growth and agglomeration of ellipsoids that we have observed with this initial concentration but without seeds. However, we observed (Fig. 18b) some secondary agglomerates with sizes about $100 \mu \mathrm{m}$ that probably correspond to the seeds of agglomerates of bipyramids that have been transformed in agglomerates of ellipsoids by growth. On the surface of these large agglomerates of seed, we can also observe the ellipsoids nucleated in the precipitation and see the difference of sizes between them (Fig. 18b). We can conclude that for concentrations higher than $8 \mathrm{~mol} \mathrm{~m}^{-3}$ we cannot have the presence of bipyramids in a stable form.
The morphology of agglomerates is the same as observed in experiments at $C_{0}=8 \mathrm{~mol} \mathrm{~m}^{-3}$ without seeding (Fig. 19a). We also observe that bigger agglomerates are formed (Fig. 19b) due to the presence of ellipsoidal seeds that stay with the same size and morphology as initially. There are just some bipyramids that adhere to their surfaces. So, we can conclude that for concentrations less than $8 \mathrm{~mol} \mathrm{~m}^{-3}$ the morphology and size of ellipsoids are still the same.

Seeding does not seem to change the mechanisms of nucleation, growth and agglomeration of bipyramids and ellipsoids. Therefore, we conclude that for a given concentration we cannot observe a morphology that usually is formed at a lower

a

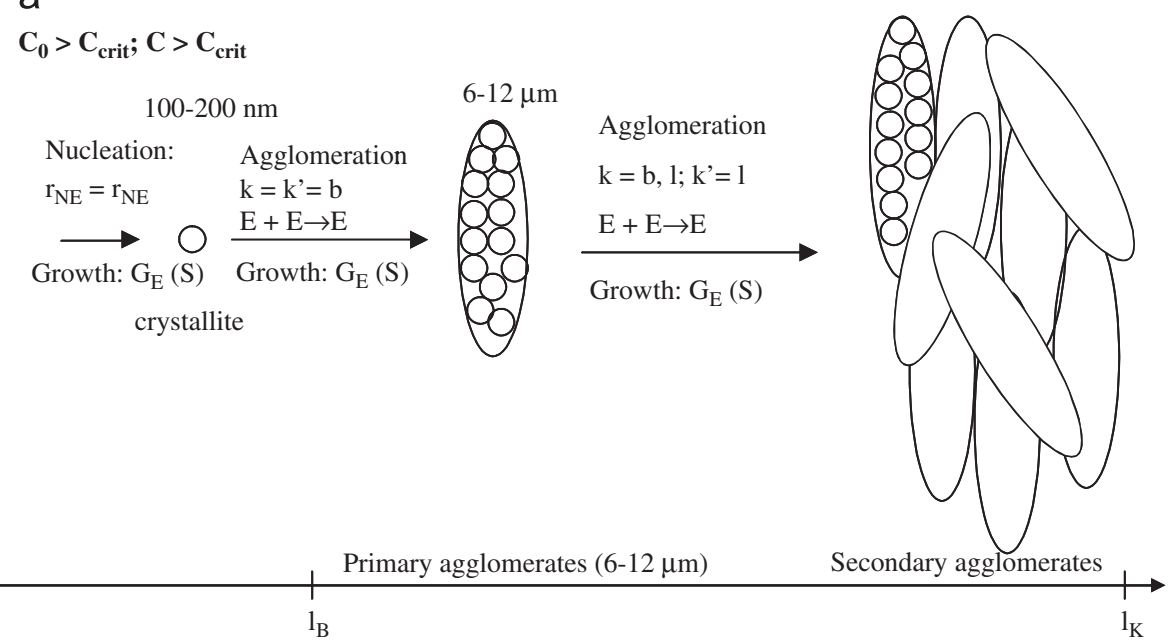

b

$\mathrm{C}_{\mathbf{0}}>\mathrm{C}_{\text {crit }} ; \mathrm{C} \leq \mathrm{C}_{\text {crit }}$

Pop. E:
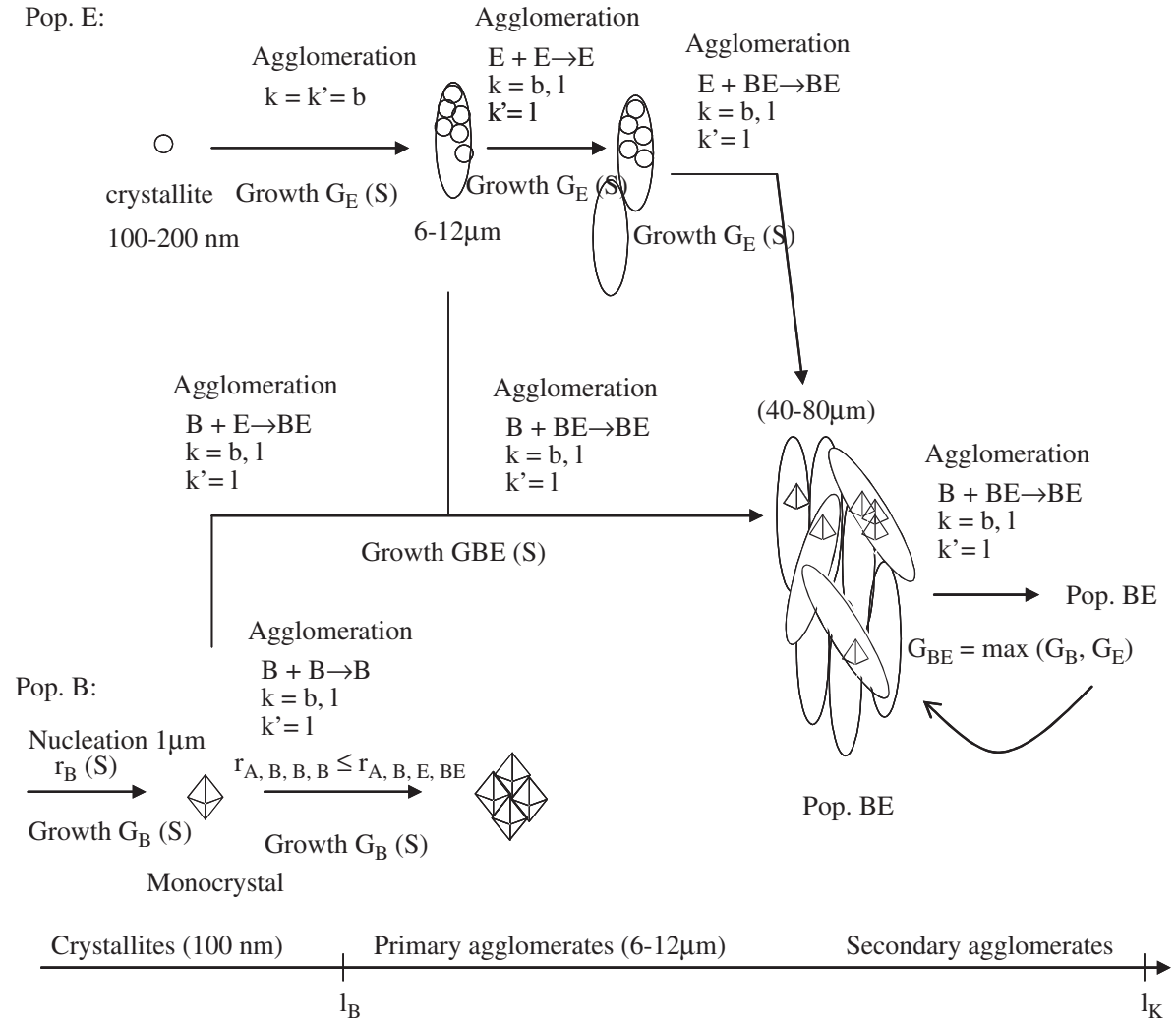

Fig. 21. Diagram with the mechanism of precipitation for $C_{0}>C_{\text {crit }}$; the desupersaturation is divided into two domains: (a) $C>C_{\text {crit }}$ and (b) $C \leqslant C_{\text {crit }}$. 
concentration: the bipyramidal seeds are growing in the morphology corresponding to the domain of higher concentrations, i.e. as ellipsoids. On the contrary, a morphology formed at a higher concentration can survive at lower concentrations.

\subsection{Mechanisms of nucleation, growth and agglomeration of the $\mathrm{SrMoO}_{4}$}

Strontium molybdate obviously presents two domains of precipitation: $\left[C_{\mathrm{eq}}, C_{\text {crit }}\right]$ and $\left[>C_{\text {crit }}\right] . C_{\text {crit }}$ is the critical concentration (equal to about $8.5 \mathrm{~mol} \mathrm{~m}^{-3}$ at $25^{\circ} \mathrm{C}$ ) corresponding to the kinetic roughening transition. The mechanisms of nucleation, growth and agglomeration of these two domains are presented in the next diagrams. The collision hydrodynamics regime noted as $k$ can be either Brownian (b) or laminar $(l)$. The hydrodynamics of the agglomerate consolidation regime $k^{\prime}$ can be either $(b)$ or $(l)$ too. The consolidation regime is the one where the aggregate formed by collision consolidates by growth of a crystalline bridge between the colliding particles [9].

The domain of precipitation for $C_{0} \leqslant C_{\text {crit }}$ can be characterised by nucleation of bipyramids (nucleation rate $r_{\mathrm{NB}}$ ), followed by their growth (growth rate $G_{\mathrm{B}}$ ) and agglomeration (agglomeration rate $A_{g g}$ ) (Fig. 20).

Fig. 21 presents the mechanism of precipitation for $C_{0}>C_{\text {crit }}$ : if the actual concentration $C$ is higher than $C_{\text {crit }}$, nucleation of ellipsoids particles $E\left(r_{\mathrm{NE}}\right)$ takes place, followed by growth $\left(G_{\mathrm{E}}\right)$ and agglomeration of ellipsoidal particles $\left(\mathrm{Agg}_{\mathrm{E}}\right)$.

The two types of crystallites and primary particles lead to the identification of three populations of agglomerates: one of bipyramids $(B)$ (if seeded), another of ellipsoids $(E)$, and a third mixed one made of agglomerates of bipyramids and ellipsoids (BE).

When the concentration during precipitation becomes lower than $C_{\text {crit }}$, nucleation of bipyramids ( rate $_{\mathrm{NB}}$ ) is followed by growth $\left(G_{B}\right)$ and agglomeration with bipyramids $(B+B \rightarrow B)$ and ellipsoidal particles $(B+E \rightarrow B E)$. In this mechanism, we assume that agglomerates $\mathrm{BE}$ are going to grow with a growth rate $G_{\mathrm{BE}}$. In turn, $\mathrm{BE}$ agglomerates can agglomerate with any other agglomerate $(B, E$ or $\mathrm{BE})$.

We conclude that the growth rates of bipyramids and ellipsoids are different because the decrease of concentrations for precipitation with $C_{0}>C_{\text {crit }}$ is less abrupt than those of precipitations with $C_{0}<C_{\text {crit }}$.

The nucleation of forms $B$ and $E$ is supposed to be defined by the same nucleation rate but the kinetics of growth is supposed to be different. The population $\mathrm{BE}$ is the result of agglomeration and not of nucleation. Its growth rate $G_{\mathrm{BE}}$ is assumed to be equal to the larger one between $G_{\mathrm{B}}$ and $G_{\mathrm{E}}$, depending on the actual concentration.

\section{Conclusions}

The morphology of strontium molybdate presents three scales of size: crystallites, (ellipsoidal or bipyramidal) primary particles and porous agglomerates. Nucleation and initial growth of crystallites are very fast for concentrations higher than $10 \mathrm{~mol} \mathrm{~m}^{-3}$.

The precipitation of strontium molybdate is very sensitive to the different initial concentration of $\mathrm{SrMoO}_{4}$. The outcome is an ellipsoidal or bipyramidal primary particle of $6-12 \mu \mathrm{m}$. The primary agglomerates continue to grow slowly and to agglomerate again into secondary agglomerates as long as the super- saturation remains positive. The upper size limit of secondary agglomerates is closely related to the Kolmogoroff microscale, indicating the major influence of hydrodynamics on secondary agglomerate building.

Initial concentration of strontium molybdate affects both structure and size of multi-level hierarchical agglomerates. The well-crystallised primary particles are probably crystallites. At low initial concentrations the primary particles are bipyramidal and the corresponding agglomerates are denser because this structure implies more compaction (faces into contact). With higher initial concentration primary particles are larger and they look like ellipsoids. The primary particles are crystallites, whose size decreases with increasing initial concentration. This structure shows a lower density because of one point of contact. At very high initial concentration primary particles are similar to cylinders with multiple extremities that increase the specific area.

The qualitative models in Figs. 20 and 21 deserve some questions:

- The first one concerns the formation of ellipsoids: are these the result of agglomeration of crystallites or of crystal growth?

- The second one concerns how the rough transition occurs and the conditions required for this transformation.

- Finally, as suggested by Glasner and Tassa [11], were our crystallites made from bloc-nuclei? At low concentrations and supersaturations the nuclei are bigger and their surface is smooth. On the contrary, at high concentrations and supersaturations the nuclei are smaller and their surface is rougher. These facts may correspond to the existence of large and small bloc-nuclei, respectively. But, as nucleation generates much less solid mass than crystalline growth, a faster desupersaturation consecutive to nucleation only via large bloc-nuclei at low concentrations seems unlikely. On the contrary, experiments show a faster desupersaturation at high concentrations. In our case crystals and agglomerates are made from crystallites. The crystallites are issued by incorporation of growth units on the nuclei surface.

Only a quantitative modelling based on all experimental results can allow us to go more into the details and to understand the mechanisms of strontium molybdate precipitation. This will be done in a further paper.

\section{References}

[1] O. Söhnel, J. Mullin, Ind. Eng. Chem. Res. 27 (1988) 1721.

[2] A. Cameirão, R. David, F. Espitalier, F. Gruy, Multiple agglomeration in strontium molybdate precipitation. In: 16th ISIC, (2005) pp. 355-360.

[3] W. Tiller, The Science of Crystallization, Cambridge University Press, Cambridge, 1991.

[4] Th.N. Zwietering, Chem. Eng. Sci. 8 (1958) 244.

[5] A. Cameirão, Etude expérimentale et modélisation d'une précipitation avec agglomération entre cristaux de morphologies différentes: application au molybdate de strontium, Ph.D. Thesis, Institut National Polytechnique de Toulouse, 2007.

[6] A. Mersmann, in: A. Mersmann (Ed.), Cristallization Technology Handbook, Marcel Dekker, New York, 1994, p. 157.

[7] P. Bennema, D.T. Hurle, Handbook of Crystal Growth-1a Fundamentals: Thermodynamics and Kinetics, Elsevier, Amsterdam, 1993, pp. 481-577.

[8] R.F.P. Grimbergen, et al., Acta Crystallogr. A 54 (1998) 491.

[9] R. David, F. Espitalier, A. Cameirão, L. Rouleau, KONA Powder Part. 21 (2003)

[10] J.W. Mullin, Cystallization, fourth ed., Butterworth Heinemann, London, 2001.

[11] A. Glasner, M. Tassa, Isr. J. Chem. 12 (4) (1974) 817.

[12] W.K. Burton, N. Cabrera, F.C. Franck, The growth of crystals and the equilibrium structure of their surfaces, Trans. Roy. Soc., A 243 (1951) 299. 